\title{
Effect of Amlodipine on the Antiepileptic Action of Lamotrigine, Gabapentin, Topiramate \& Carbamazepine on Pentylenetetrazole and Maximal Electroshock Induced Seizures in Rats
}

\author{
Dr. Ratna Agrawal ${ }^{*}$, Dr. Kaustav Saha ${ }^{2}$, Dr. Sabita Mohapatra ${ }^{3}$ \\ ${ }^{1,2}$ Postgraduate student, Department of Pharmacology, V. S. S .Medical College, Burla, Sambalpur, \\ Odisha, India \\ ${ }^{3}$ Prof \& HOD,Department of Pharmacology, V. S. S.Medical College, Burla, Sambalpur, Odisha, India
}

\begin{abstract}
Introduction: The trials for epilepsy treatment have increased with the introduction of newer antiepileptics like lamotrigine, gabapentin, topiramate. Calcium ion has important role in pathophysiology of epilepsy. Aim of the present study was to assess the effects of calcium channel antagonist amlodipine on the antiepileptic action of lamotrigine, gabapentin, topiramate, carbamazepine on pentylenetetrazole(PTZ) and Maximal electro shock seizure (MES) models in rats.

Material and methods: Two hundred forty adult healthy wistar albino rats divided into 40 groups in 6 each. Half of the groups were alloted for each of both PTZ and MES model. Control (normal saline) and different doses of amlodipine $(0.25,0.5,1 \mathrm{mg} / \mathrm{kg})$ were administered intraperitoneally. Lamotrigine $(18 \mathrm{mg} / \mathrm{kg})$, gabapentin $(60 \mathrm{mg} / \mathrm{kg})$, topiramate $(36 \mathrm{mg} / \mathrm{kg})$, carbamazepine $(72 \mathrm{mg} / \mathrm{kg})$ were administered separately. Different doses of amlodipine was combined with lamotrigine $(18 \mathrm{mg} / \mathrm{kg})$, gabapentin $(60 \mathrm{mg} / \mathrm{kg}$ ), topiramate (36 $\mathrm{mg} / \mathrm{kg})$, carbamazepine $(72 \mathrm{mg} / \mathrm{kg})$. In PTZ model we observed for onset, duration and number of seizure. In MES model the onset and duration of tonic hind limb extension (THLE) was measured.

Results: Amlodipine at moderate and high doses produced significant anticonvulsant effect and increased the anticonvulsant action of lamotrigine, gabapentin, topiramate and carbamazepine in a dose dependent manner in both PTZ and MES seizure models.

Conclusion: The potential effect of amlodipine on various antiepileptic drugs is due to its action over various channels and neurotransmitter released. The results of this study deserve more attention as it can be a favourable treatment modality in patients of epilepsy with hypertension.
\end{abstract}

Keywords: Calcium channel blocker, Anticonvulsants, MES, PTZ

\section{Introduction}

Calcium ions have important role in pathophysiology of epilepsy. ${ }^{[1]} \mathrm{A}$ decrease in extracellular calcium concentration prior to onset of seizure activity is followed by an increase in the intracellular calcium concentration. ${ }^{[1]}$ Generally, it is thought that the blockade of high voltage activated (L, N, P/Q type) calcium channels are associated with control of partial seizures with or without secondary generalization. ${ }^{[2]}$ Calcium channel antagonists readily penetrating into the brain potentiated the protective efficacy of some antiepileptic drugs in both preclinical and clinical studies. Several reports have revealed beneficial effects of some calcium channel antagonists (flunarizine, cinnarizine and nimodipine) as add-on treatment in epileptic patients. ${ }^{[3-7]} \mathrm{A}$ reduced release of excitatory transmitters, including glutamate, is one of the consequences of calcium channel blockade ${ }^{[8]}$ Considering the fact that seizure activity depends on calcium ion and some antiepileptic drugs interfere with calcium ion fluxes, we attempted to study the effects of amlodipine, a dihydropyridine type calcium channel antagonist on the protective activity of lamotrigine, gabapentin, topiramate \& carbamazepine in the rats by pentylenetetrazole (PTZ)and Maximal electroshock seizure(MES) induced seizure model.

\section{Materials \& Methods}

The study was conducted on healthy adult albino wistar rats (150-250gm) of either sex. They were housed in the departmental animal house, in cages, in temperature regulated rooms with air cooling and 12 hour light and dark cycle, under standard laboratory conditions and fed with standard animal feed and were given water ad libitum. They were allowed to acclimatize to the laboratory conditions for a period of one week. The experiment protocol was approved by the Institutional animal ethics committee and was executed according to the guidelines of Committee for the purpose of control and supervision on experiment on animals (CPCSEA), India. Two hundred forty adult wistar rats divided into 40 groups in 6 each. 


\subsection{Drugs used}

Amlodipine besylate was obtained from Macleods Pharmaceuticals Ltd., Himachal Pradesh, India.

Gabapentin was obtained from Intas Pharmaceuticals Ltd., Sikkim, India.

Lamotrigine was obtained from Torrent Pharmaceuticals Ltd. India.

Topiramate was obtained from Intas Pharmaceuticals Ltd., Sikkim, India.

Carbamazepine was obtained from Intas Pharmaceuticals Ltd., Sikkim, India.

All the drugs were dissolved in normal saline \&clear fresh drug solutions were administered intraperitoneally. The animal doses of all the drugs were extrapolated from human dose.

The baseline reaction time was obtained at the start of experiment $(0 \mathrm{hrs})$ just before the drug administration. Tests were performed after different time interval of administration as the time to peak action of drugs were different. Different doses of amlodipine were administered to search for anticonvulsant activity. Amlodipine and lamotrigine were administered $120 \mathrm{~min}$ and $60 \mathrm{~min}$ before respectively while both gabapentin and carbamazepine were administered $30 \mathrm{~min}$ before PTZ and MES. In the groups receiving combined treatment, the two drugs were administered at different times. After observing baseline $(0 \mathrm{hr})$ reaction time at the start of experiment amlodipine was administered. Lamotrigine was administered 60 mins after administration of amlodipine and both PTZ and MES were performed further 60 min after. Gabapentin and carbamazepine was administered 90 min after administration of amlodipine while TFL tests were done after 30 min further.

\subsection{Pentylenetetrazole induced convulsion model}

PTZ model induces seizure which resembles human absence seizure. PTZ was given at a dose of $40 \mathrm{mg} / \mathrm{kg}$ after pretreatment with the medications. Animals were observed for $60 \mathrm{~min}$. The onset, duration and number of seizures within $60 \mathrm{~min}$ were assessed to determine anticonvulsant action. The drugs were administered according to Table 1.

TABLE 1- Doses administered in PTZ model

\begin{tabular}{|l|l|l|}
\hline Group & Drugs & Dose $(\mathbf{m g} / \mathbf{k g})$ \\
\hline 1. & Normal Saline + PTZ & $5 \mathrm{ml} / \mathrm{kg}+40$ \\
\hline 2. & Amlodipine + PTZ & $0.25+40$ \\
\hline 3. & Amlodipine + PTZ & $0.5+40$ \\
\hline 4. & Amlodipine + PTZ & $1+40$ \\
\hline 5. & Lamotrigine + PTZ & $18+40$ \\
\hline 6. & Gabapentin + PTZ & $60+40$ \\
\hline 7. & Topiramate + PTZ & $36+40$ \\
\hline 8. & Carbamazepine + PTZ & $72+40$ \\
\hline 9. & Lamotrigine+Amlodipine+ PTZ & $18+0.25+40$ \\
\hline 10. & Lamotrigine+Amlodipine+ PTZ & $18+0.5+40$ \\
\hline 11. & Lamotrigine+Amlodipine+ PTZ & $18+1+40$ \\
\hline 12 & Gabapentin+Amlodipine+ PTZ & $60+0.25+40$ \\
\hline 13. & Gabapentin+Amlodipine+ PTZ & $60+0.5+40$ \\
\hline 14. & Gabapentin+Amlodipine+ PTZ & $60+1+40$ \\
\hline 15. & Topiramate+Amlodipine+ PTZ & $36+0.25+40$ \\
\hline 16. & Topiramate+Amlodipine+ PTZ & $36+0.5+40$ \\
\hline 17. & Topiramate+Amlodipine+ PTZ & $36+1+40$ \\
\hline 18. & Carbamazepine+Amlodipine+ PTZ & $72+0.25+40$ \\
\hline 19. & Carbamazepine+Amlodipine+ PTZ & $72+0.5+40$ \\
\hline 20. & Carbamazepine+Amlodipine+ PTZ & $72+1+40$ \\
\hline
\end{tabular}

\subsection{Maximal electroshock seizure model}

The apparatus used was electroconvulsiometer (INCO Ambala Instruments \& Chemicals Pvt. Ltd.).

MES is a model for grand mal epilesy \& the end point is considered as tonic hind limb extension(THLE) which are evoked by electrical stimuli (i.e. the hind limbs of animals outstretched $180^{\circ}$ to the plane of the body axis). The maximal electroshock is induced through ear electrode. A $50 \mathrm{~Hz}$ stimulus of 0.2 seconds duration was applied through saline wet ear electrodes. The current that produced convulsions with tonic hind limb extension was $150 \mathrm{~mA}$. This current was used throughout the study. The anticonvulsant activity of lamotrigine, gabapentin, topiramate and carbamazepine co-administered with amlodipine, as described in Table 2, was evaluated by their respective onset and duration of THLE.

Table 2- Doses administered in MES model

\begin{tabular}{|l|l|l|}
\hline Group & Drugs & Dose $(\mathbf{m g} / \mathbf{k g})$ \\
\hline 21. & Normal Saline & $5 \mathrm{ml} / \mathrm{kg}$ \\
\hline 22. & Amlodipine & 0.25 \\
\hline 23. & Amlodipine & 0.5 \\
\hline
\end{tabular}


Effect of Amlodipine on the Antiepileptic Action of Lamotrigine, Gabapentin, Topiramate \&...

\begin{tabular}{|l|l|l|}
\hline 24. & Amlodipine & 1 \\
\hline 25. & Lamotrigine & 18 \\
\hline 26. & Gabapentin & 60 \\
\hline 27. & Topiramate & 36 \\
\hline 28. & Carbamazepine & 72 \\
\hline 29. & Lamotrigine+Amlodipine & $18+0.25$ \\
\hline 30. & Lamotrigine+Amlodipine & $18+0.5$ \\
\hline 31. & Lamotrigine+Amlodipine & $18+1$ \\
\hline 32 & Gabapentin+Amlodipine & $60+0.25$ \\
\hline 33. & Gabapentin+Amlodipine & $60+0.5$ \\
\hline 34. & Gabapentin+Amlodipine & $60+1$ \\
\hline 35. & Topiramate+Amlodipine & $36+0.25$ \\
\hline 36. & Topiramate+Amlodipine & $36+0.5$ \\
\hline 37. & Topiramate+Amlodipine & $36+1$ \\
\hline 38. & Carbamazepine+Amlodipine & $72+0.25$ \\
\hline 39. & Carbamazepine+Amlodipine & $72+0.5$ \\
\hline 40. & Carbamazepine+Amlodipine & $72+1$ \\
\hline
\end{tabular}

\subsection{Statistical analysis}

Data were entered in Graph Pad Prism version 6.0 and analyzed using one way ANOVA followed by the post-hoc Bonferroni test for multiple comparisons. Differences among values were considered statistically significant if $\mathrm{p}<0.05$.

\section{Results}

Table3- Effect of amlodipine, anticonvulsants and their combinations on onset, duration and number of seizures in PTZ model

\begin{tabular}{|c|c|c|c|c|c|}
\hline Group & Drugs \& combinations & Dose (mg/kg) & Onset of seizure & Duration of seizures & Number of seizures in $60 \mathrm{~min}$ \\
\hline 1. & Normal Saline & $1.5 \mathrm{ml} / \mathrm{kg}$ & $4.1 \pm 0.735$ & $12.7 \pm 0.094$ & $3 \pm 0.842$ \\
\hline 2. & Amlodipine & 0.25 & $4.23 \pm 0.13$ & $12.3 \pm 0.415$ & $3 \pm 0.973$ \\
\hline 3. & Amlodipine & 0.5 & $4.78 \pm 0.586^{*}$ & $11.69 \pm 0.124^{*}$ & $3 \pm 0.34$ \\
\hline 4. & Amlodipine & 1 & $6.12 \pm 0.753^{*}$ & $10.98 \pm 0.723^{*}$ & $2 \pm 0.94 *$ \\
\hline 5. & Lamotrigine & 18 & $6.30 \pm 0.941 *$ & $10.86 \pm 0.539 *$ & $1 \pm 0.78^{*}$ \\
\hline 6. & Gabapentin & 60 & $6.95 \pm 0.206^{*}$ & $10.73 \pm 0.804^{*}$ & $1 \pm 0.68 *$ \\
\hline 7. & Topiramate & 36 & $7.24 \pm 0.188^{*}$ & $10.43 \pm 0.165^{*}$ & $1 \pm 0.57 *$ \\
\hline 8. & Carbamazepine & 72 & $8.8 \pm 0.551^{*}$ & $9.81 \pm 0.715^{*}$ & $1 \pm 0.48^{*}$ \\
\hline 9. & $\begin{array}{l}\text { Lamotrigine } \\
\text { Amlodipine }\end{array}$ & $18+0.25$ & $12.12 \pm 0.755^{*}$ & $7.21 \pm 0.130^{*}$ & $1 \pm 0.88^{*}$ \\
\hline 10. & $\begin{array}{l}\text { Lamotrigine } \\
\text { Amlodipine }\end{array}$ & $18+0.5$ & $14.52 \pm 0.722^{*}$ & $6.6 \pm 0.185^{*}$ & $1 \pm 0.72 *$ \\
\hline 11. & $\begin{array}{l}\text { Lamotrigine } \\
\text { Amlodipine }\end{array}$ & $18+1$ & $15.34 \pm 0.556^{*}$ & $6.16 \pm 0.297^{*}$ & $1 \pm 0.43^{*}$ \\
\hline 12. & $\begin{array}{l}\text { Gabapentin } \\
\text { Amlodipine }\end{array}$ & $60+0.25$ & $12.85 \pm 0.704^{*}$ & $6.82 \pm 0.055^{*}$ & $1 \pm 0.78^{*}$ \\
\hline 13. & $\begin{array}{l}\text { Gabapentin } \\
\text { Amlodipine }\end{array}$ & $60+0.5$ & $14.57 \pm 0.882^{*}$ & $5.98 \pm 0.179^{*}$ & $1 \pm 0.49^{*}$ \\
\hline 14. & $\begin{array}{l}\text { Gabapentin } \\
\text { Amlodipine }\end{array}$ & $60+1$ & $16.17 \pm 0.99 *$ & $5.48 \pm 0.196^{*}$ & $1 \pm 0.35^{*}$ \\
\hline 15. & $\begin{array}{l}\text { Topiramate } \\
\text { Amlodipine }\end{array}$ & $36+0.25$ & $18.68 \pm 0.764^{*}$ & $5.45 \pm 0.633^{*}$ & $1 \pm 0.6^{*}$ \\
\hline 16. & $\begin{array}{l}\text { Topiramate } \\
\text { Amlodipine }\end{array}$ & $36+0.5$ & $22.5 \pm 0.531 *$ & $4.97 \pm 0.335^{*}$ & $1 \pm 0.28^{*}$ \\
\hline 17. & $\begin{array}{l}\text { Topiramate } \\
\text { Amlodipine }\end{array}$ & $36+1$ & $24.82 \pm 0.775^{*}$ & $4.68 \pm 0.175^{*}$ & $1 \pm 0.21 *$ \\
\hline 18. & $\begin{array}{l}\text { Carbamazepine } \\
\text { Amlodipine }\end{array}$ & $72+0.25$ & $22.27 \pm 0.76^{*}$ & $5.85 \pm 0.779^{*}$ & $1 \pm 0.55^{*}$ \\
\hline 19. & $\begin{array}{l}\text { Carbamazepine } \\
\text { Amlodipine }\end{array}$ & $72+0.5$ & $23.85 \pm 0.729 *$ & $4.95 \pm 0.056^{*}$ & $1 \pm 0.3^{*}$ \\
\hline 20. & $\begin{array}{l}\text { Carbamazepine } \\
\text { Amlodipine }\end{array}$ & $72+1$ & $25.38 \pm 0.911^{*}$ & $4.66 \pm 0.123^{*}$ & $1 \pm 0.17^{*}$ \\
\hline
\end{tabular}

$(* \mathrm{P}<0.05$, statistically significant $)$

Intraperitoneal administration of amlodipine produced a significant anticonvulsant effect against control in PTZ induced seizures in rats. Amlodipine in a dose-dependent manner, increased the latency and decreased the duration of seizure significantly at all doses of it $(0.25,0.5$ and $1 \mathrm{mg} / \mathrm{kg})$ as depicted in Fig. 1 . Decreased number of seizures was found with highest dose amlodipine $(1 \mathrm{mg} / \mathrm{kg})$. 


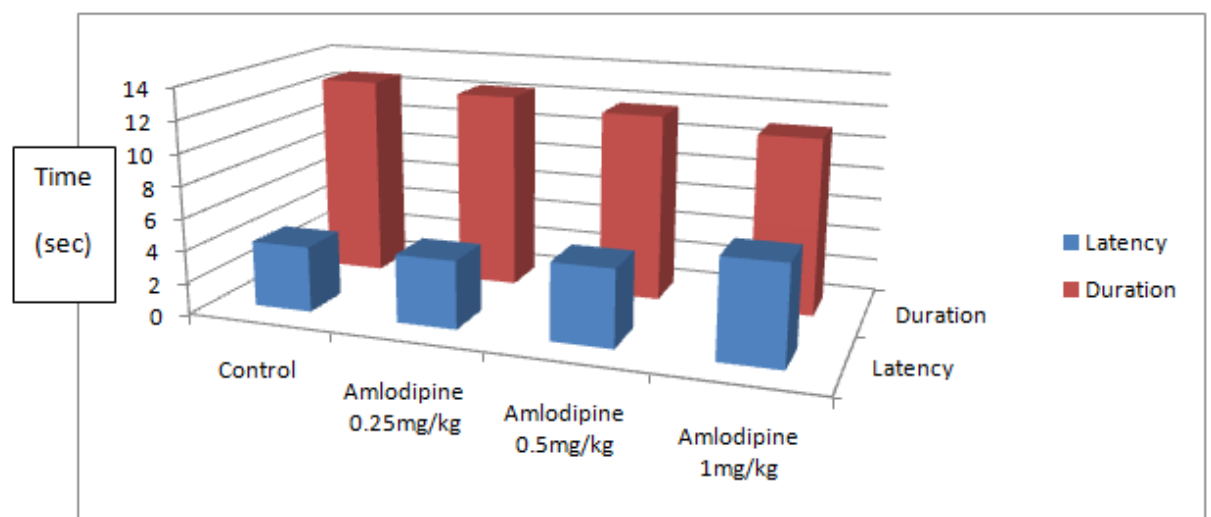

FIGURE 1 : effect of amlodipine on the onset and duration of seizures in ptz induced seizure model

Intraperitoneal administration of lamotrigine produced a significant anticonvulsant effect against control in PTZ induced seizures in rats. Amlodipine co-administered with lamotrigine delayed the onset and decreased the duration of seizure significantly in a dose-dependent manner $(0.25,0.5$ and $1 \mathrm{mg} / \mathrm{kg})$ as depicted in Fig. 2. The combination also decreased number of seizures.

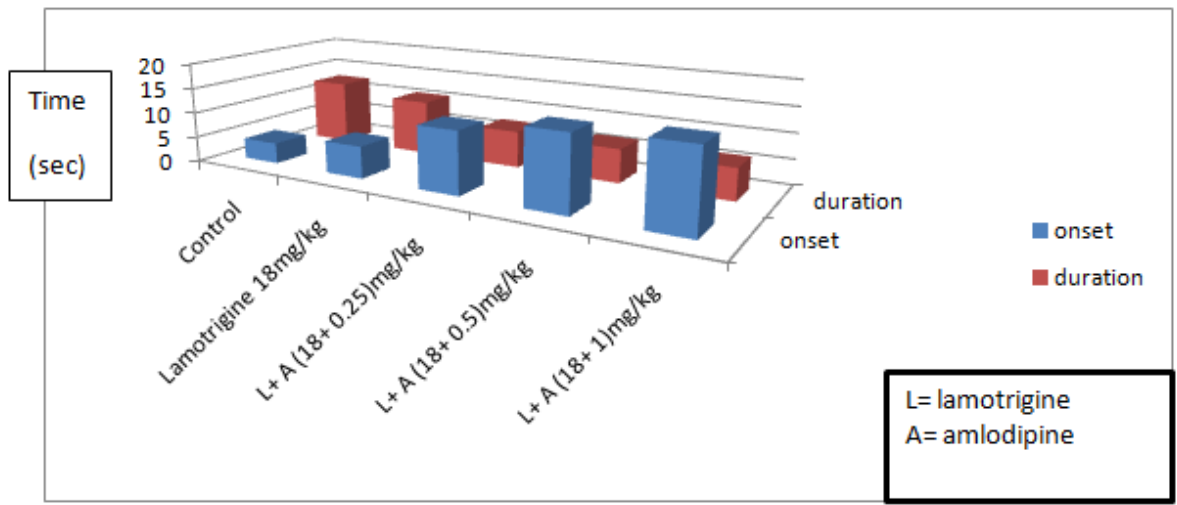

Figure 2 : effect of amlodipine on the anticonvulsant action of lamotrigine in ptz induced seizure model

Intraperitoneal administration of gabapentin produced a significant anticonvulsant effect against control in PTZ induced seizures in rats. Amlodipine co-administered with gabapentin delayed the onset and decreased the duration of Seizure significantly in a dose-dependent manner $(0.25,0.5 \mathrm{and} 1 \mathrm{mg} / \mathrm{kg})$ as depicted in Fig. 3. Number of seizures also decreased.

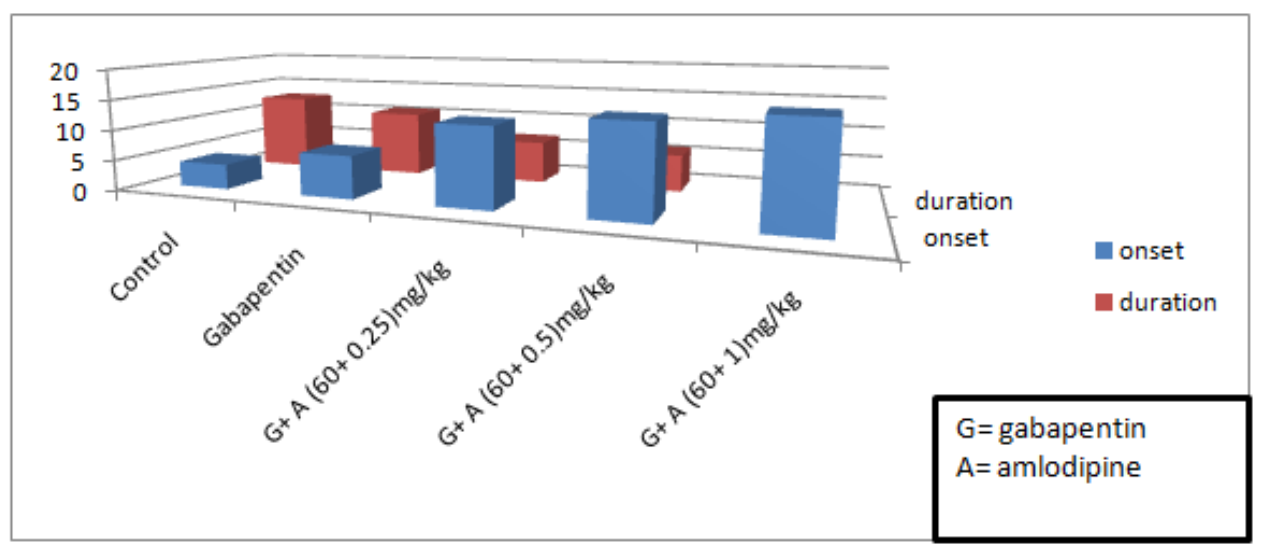

Figure 3: effects of amlodipine on the anticonvulsant action of gabapentin in ptz induced seizure model

Topiramate i.p. produced significant anticonvulsant effect in PTZ induced seizures in rats. Amlodipine co-administered with topiramate delayed the onset and decreased the duration of seizure significantly in a dosedependent manner $(0.25,0.5$ and $1 \mathrm{mg} / \mathrm{kg})$ as depicted in Fig. 4 . Number of seizure also decreased significantly. 


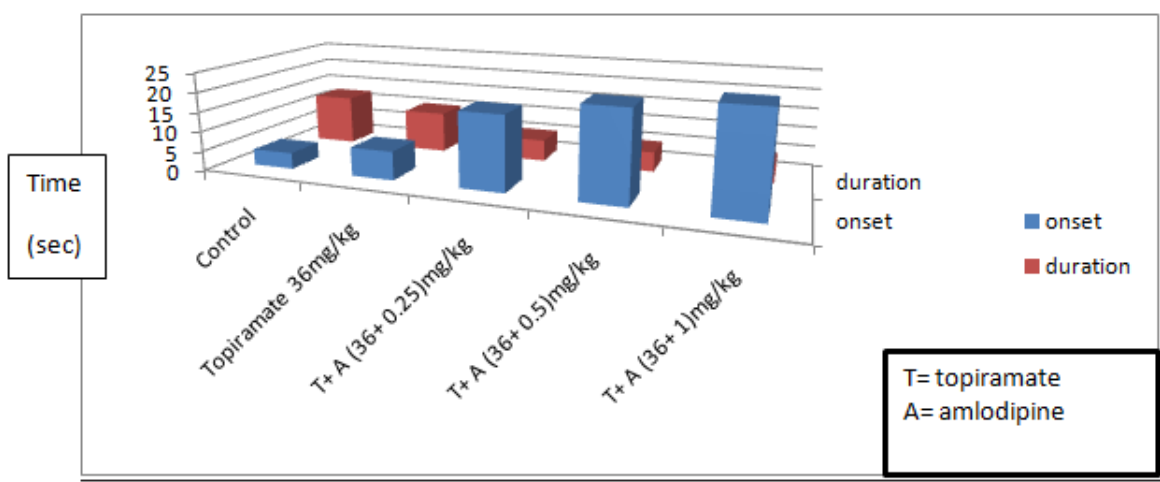

Figure 4: effects of amlodipine on the anticonvulsant action of topiramate in ptz induced seizure model

I.P. carbamazepine produced a significant anticonvulsant effect against control in PTZ induced seizures in rats. Amlodipine co-administered with carbamazepine delayed the onset and decreased the duration of seizure significantly at all doses of it $(0.25,0.5$ and $1 \mathrm{mg} / \mathrm{kg})$ as depicted in Fig. 5 . There was also decrease in number of seizures.

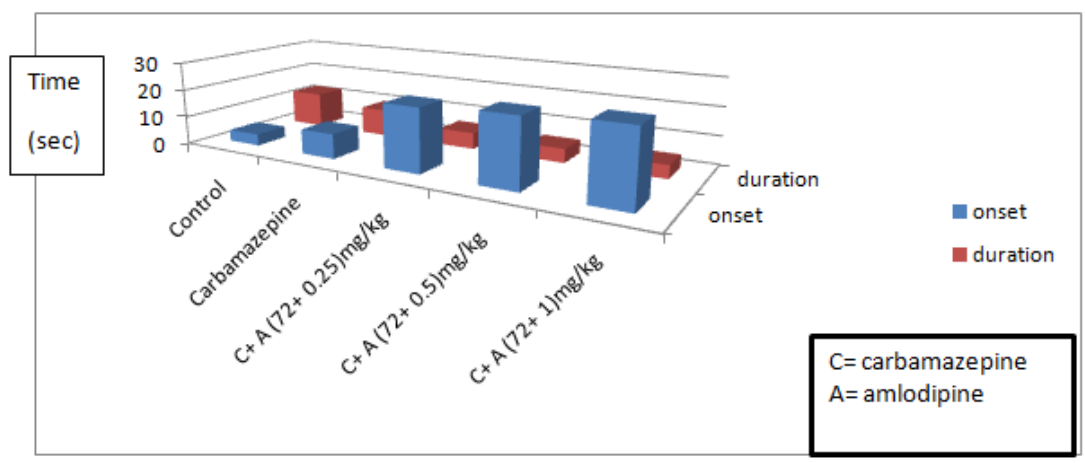

Figure 5: effects of amlodipine on the anticonvulscent action of carbamazepine against ptz induced seizure model

TABLE 4: Effect of drugs \& their combinations on THLE onset and duration in MES model

\begin{tabular}{|l|l|l|l|l|}
\hline Group & Drugs & Dose $(\mathbf{m g} / \mathbf{k g})$ & $\begin{array}{l}\text { Onset of THLE } \\
\text { (Mean } \pm \text { SEM) }\end{array}$ & $\begin{array}{l}\text { Duration of THLE } \\
\text { (Mean } \pm \text { SEM) }\end{array}$ \\
\hline 21. & Normal Saline & $1.5 \mathrm{ml} / \mathrm{kg}$ & $4.28 \pm 0.346$ & $13.4 \pm 0.309$ \\
\hline 22. & Amlodipine & 0.25 & $3.78 \pm 0.094$ & $13.7 \pm 0.415$ \\
\hline 23. & Amlodipine & 0.5 & $4.98 \pm 0.166^{*}$ & $11.85 \pm 0.165^{*}$ \\
\hline 24. & Amlodipine & 1 & $5.63 \pm 0.133^{*}$ & $10.98 \pm 0.133^{*}$ \\
\hline 25. & Lamotrigine & 18 & $5.63 \pm 0.149^{*}$ & $11.2 \pm 0.239^{*}$ \\
\hline 26. & Gabapentin & 60 & $7.00 \pm 0.206^{*}$ & $10.75 \pm 0.204^{*}$ \\
\hline 27. & Topiramate & 36 & $6.83 \pm 0.128^{*}$ & $10.63 \pm 0.154^{*}$ \\
\hline 28. & Carbamazepine & 72 & $8.03 \pm 0.18^{*}$ & $8.85 \pm 0.215^{*}$ \\
\hline 29. & Lamotrigine + Amlodipine & $18+0.25$ & $13.72 \pm 0.235^{*}$ & $6.68 \pm 0.130^{*}$ \\
\hline 30. & Lamotrigine + Amlodipine & $18+0.5$ & $15.42 \pm 0.202^{*}$ & $5.9 \pm 0.112^{*}$ \\
\hline 31. & Lamotrigine + Amlodipine & $18+1$ & $16.93 \pm 0.256^{*}$ & $5.12 \pm 0.107^{*}$ \\
\hline 32. & Gabapentin + Amlodipine & $60+0.25$ & $13.55 \pm 0.108^{*}$ & $6.82 \pm 0.094^{*}$ \\
\hline 33. & Gabapentin + Amlodipine & $60+0.5$ & $15.27 \pm 0.212^{*}$ & $5.87 \pm 0.149^{*}$ \\
\hline 34. & Gabapentin + Amlodipine & $60+1$ & $17.17 \pm 0.17^{*}$ & $5.23 \pm 0.176^{*}$ \\
\hline 35. & Topiramate + Amlodipine & $36+0.25$ & $19.68 \pm 0.224^{*}$ & $5.45 \pm 0.164^{*}$ \\
\hline 36. & Topiramate + Amlodipine & $36+0.5$ & $23.7 \pm 0.231^{*}$ & $4.77 \pm 0.055^{*}$ \\
\hline 37. & Topiramate + Amlodipine & $36+1$ & $25.72 \pm 0.135^{*}$ & $4.40 \pm 0.068^{*}$ \\
\hline 38. & Carbamazepine + Amlodipine & $72+0.25$ & $22.35 \pm 0.24^{*}$ & $5.35 \pm 0.111^{*}$ \\
\hline 39. & Carbamazepine + Amlodipine & $72+0.5$ & $25.35 \pm 0.259^{*}$ & $4.62 \pm 0.090^{*}$ \\
\hline 40. & Carbamazepine + Amlodipine & $72+1$ & $26.58 \pm 0.104^{*}$ & $4.1 \pm 0.096^{*}$ \\
\hline
\end{tabular}

$(* \mathrm{P}<0.05$, statistically significant $)$

Intraperitoneal inj. of amlodipine at doses of $0.25,0.5$ and $1 \mathrm{mg} / \mathrm{kg}$ (120 min before electro shock) was given to groups 22,23 and 24 respectively. The low dose has not showed any significant change in onset and duration of seizure in MES model whereas medium and high dose have showed some anticonvulsant effect as shown in Fig. 6. 


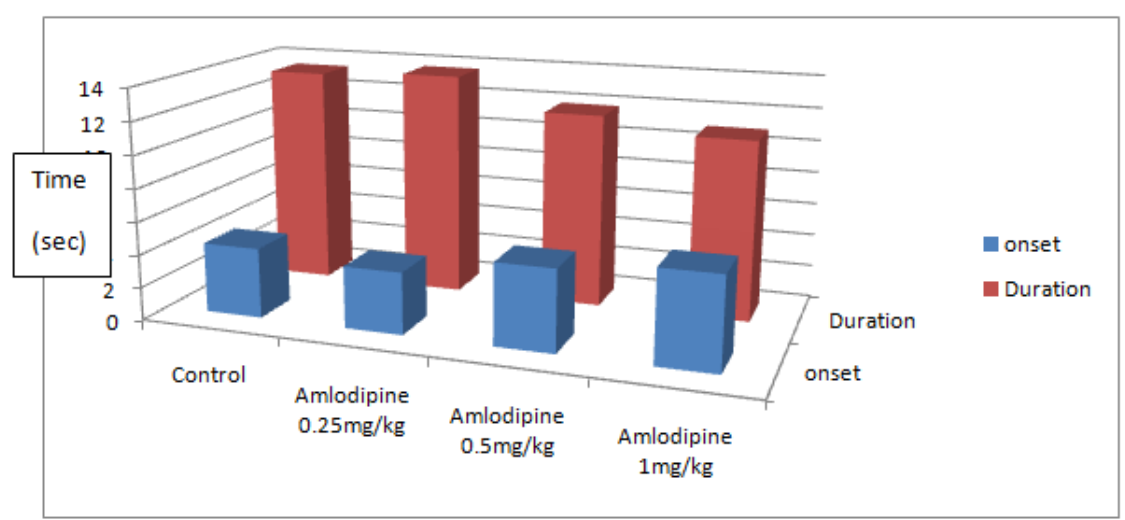

Figure 6: effect of amlodipine on the onset and duration of mes induced convulsions

Amlodipine at all doses $(0.25,0.5$ and $1 \mathrm{mg} / \mathrm{kg})$ co-administered with lamotrigine $(18 \mathrm{mg} / \mathrm{kg})$ intraperitoneally significantly decreased the duration of THLE and delayed the onset of seizures in comparison to control and lamotrigine alone as depicted in Fig. 7.

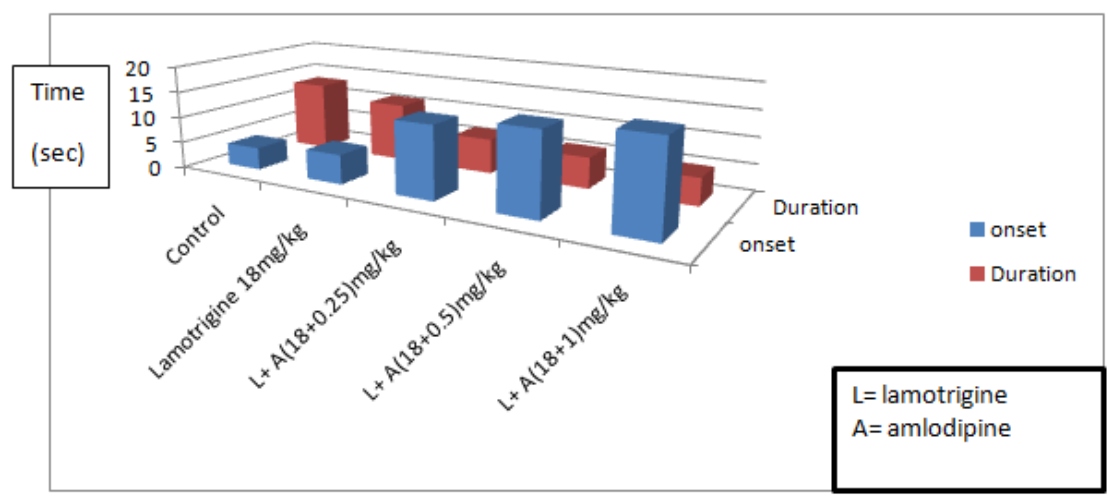

Figure 7: effect of amlodipine on lamotrigine by the onset and duration of seizure in mes induced seizure model in rats

Amlodipine at all doses $(0.25,0.5$ and $1 \mathrm{mg} / \mathrm{kg})$ co-administered with gabapentin $(60 \mathrm{mg} / \mathrm{kg})$ intraperitoneally significantly decreased the duration of THLE and delayed the onset of seizures in comparison to control and gabapentin alone as depicted in Fig. 8.

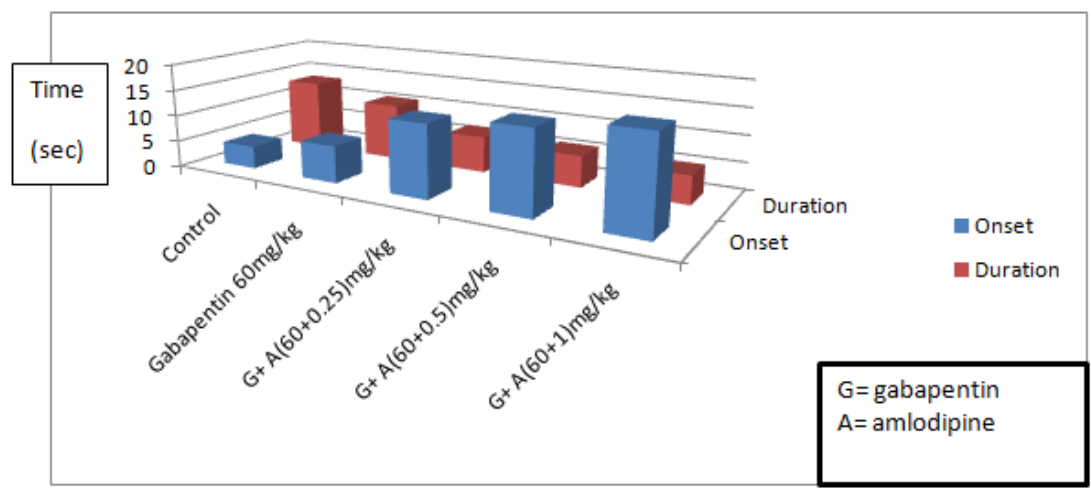

Figure 8: effect of amlodipine on gabapentin by the onset and duration of seizure in mes induced seizure model in rats

Amlodipine at all doses $(0.25,0.5$ and $1 \mathrm{mg} / \mathrm{kg})$ co-administered with topiramate $(36 \mathrm{mg} / \mathrm{kg})$ intraperitoneally significantly decreased the duration of THLE and delayed the onset of seizures in comparison to control and topiramate alone as depicted in Fig. 9. 




Figure 9: effect of amlodipine on topiramate by the onset and duration of seizure in mes induced seizure model in rats

Amlodipine at all doses $(0.25,0.5$ and $1 \mathrm{mg} / \mathrm{kg})$ co-administered with carbamazepine $(72 \mathrm{mg} / \mathrm{kg})$ intraperitoneally significantly decreased the duration of THLE and delayed the onset of seizures in comparison to control and carbamazepine alone as depicted in Fig. 10.

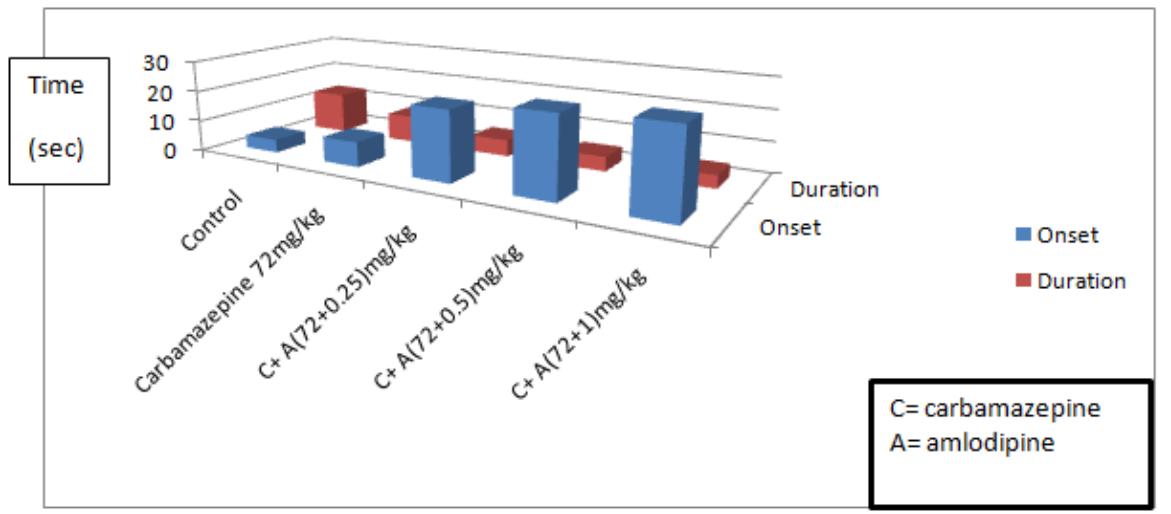

Figure 10: effect of amlodipine on carbamazepine by the onset and duration of seizure in mes induced seizure model in rats

\section{Discussion}

The present study was designed to assess the effect of amlodipine on the anticonvulsant action of lamotrigine, gabapentin, topiramate and a conventional anticonvulsant carbamazepine against PTZ and MES seizure models in rats. It was found that amlodipine alone (upto $0.25 \mathrm{mg} / \mathrm{kg}$ ) did not affect the electroconvulsive threshold in rats and this finding is partially in agreement with those documented earlier by Kaminski et al. $1999 .{ }^{[9]}$ Stefani et al showed amlodipine at dose of $0.5 \mathrm{mg} / \mathrm{kg}$ potentiated the anticonvulsant action of carbamazepine in MES induced seizure ${ }^{[10]}$ In the present study, amlodipine at all the three doses significantly enhanced the anticonvulsant action of lamotrigine, gabapentin, topiramate and carbamazepine in both seizure models in rats. ${ }^{[10]}$

To explain the interaction between lamotrigine and amlodipine against seizure, one should consider molecular mechanisms of action of both drugs. As regarding the anticonvulsant effect of lamotrigine, it has been documented that the drug acts at voltage-dependent sodium channels to decrease the presynaptic release of the excitatory neurotransmitter glutamate ${ }^{[10]}$ Moreover, lamotrigine decreases voltage-gated calcium currents and this effect, probably, contributes to a decrease in glutamate release. ${ }^{[10]}$ On the other hand, experimental evidence indicates that $\mathrm{N}$-type calcium channels are responsible for glutamate release in the cerebral cortex and hippocampus. ${ }^{[11]}$ Apart from L- type, amlodipine blocks N- and P/Q-type calcium channels showing high affinity for both these channels. ${ }^{[12,13]} \mathrm{We}$ can assume that amlodipine through the blockade of $\mathrm{N}$ - and P/Q- type calcium channels enhances the effect of lamotrigine related to the reduction of glutamate release from neurons. This hypothesis can readily explain the observed interaction between lamotrigine and amlodipine in both the seizure models in rats.

Regarding the anti-epileptic effect of gabapentin, the present study is supported by the findings of Mclean (1995)who studied the effect of gabapentin on the MES animal models. ${ }^{[14]}$ The author reported that gabapentin was as potent as phenytoin and this is explained by the possibility of enhancing the ratio of gammaamino butyric acid(GABA) and glutamate, ion-channel actions and/ or enhancement of non synaptic GABA 
release ${ }^{[15-17]}$ The favorable interaction between gabapentin and amlodipine in the MES model may be due to gabapentin increases the release of several monoamine neurotransmitters (e.g. norepinephrine) and inhibits glutamate synthesis by branched-chain amino acid aminotransferase. ${ }^{[18]}$ It also may modulate calcium channels. ${ }^{[19]}$

Topiramate is an antiepileptic drug sharing multiple mechanisms of action. This antiepileptic drug inhibits voltage-dependent sodium and L-type calcium channels, potentiates GABA mediated inhibitory neurotransmission through binding to a novel site on the GABA-A receptor complex and reduces excitatory neurotransmission by blocking $\alpha$-amino-3-hydroxy-5-methyl-4-isoxazolepropionic acid (AMPA) and kainate subtypes of glutamate receptors. ${ }^{[20-22]}$ Its effect on calcium channels may explain the interaction with amlodipine. $^{[20]}$

Carbamazepine at therapeutically relevant concentrations, reduce high frequency repetitive firing of neurons by an action on sodium channels \& enhance potassium currents. ${ }^{[23]}$ It is reported by Kaminski $\mathrm{R}$ et al that, calcium channel blockers increase the free plasma concentration of carbamazepine and thus increases the anticonvulsant activity. ${ }^{[9]}$

\section{Conclusion}

Amlodipine potentiates the anticonvulsant action of lamotrigine, gabapentin, topiramate and carbamazepine in a dose dependent manner. Amlodipine alone showed anticonvulsant action at high doses. If the results from this study can be extrapolated to the clinical settings, a novel therapeutic option in the management of epilepsy might be created, where it could be used as adjunct in epileptic patients treated with lamotrigine, gabapentin, topiramate or carbamazepine who additionally required a calcium channel antagonist treatment for other than epilepsy reasons.

\section{Acknowledgements}

We are thankful to all the staffs of Department of Pharmacology, V. S. S. Medical College, Burla, Sambalpur, Odisha, India.

\section{References}

[1]. Beck H, Steffens R, Heinemann U, Elger CE. $\mathrm{Ca}^{2+}$ - dependent inactivation of high-threshold Ca (2+) currents in hippocampal granule cells of patients with chronic temporal lobe epilepsy. J Neurophysiol 1999;82:946-54.

[2]. Cain SM, Snutch TP. Voltage-Gated Calcium Channels in Epilepsy. In: Noebels JL, Avoli M, Rogawski MA, et al., editors. Jasper's Basic Mechanisms of the Epilepsies [Internet]. 4th edition. Bethesda (MD): National Center for Biotechnology Information (US); 2012. Available from: http://www.ncbi.nlm.nih.gov/books/NBK98147/

[3]. Binnie CD, de Beukelaar F, Meijer JW, Meinardi H, Overweg J, Wauquier A, van Wieringen A: Open doseranging trial of flunarizine as add-on therapy in epilepsy. Epilepsia, 1985, 26, 424-428.

[4]. De Falco FA, Bartiromo U, Majello L, Di Geronimo G, Mundo P: Calcium antagonist nimodipine in intractable epilepsy. Epilepsia, 1992, 33, 343-345.

[5]. Nakane Y, Seino M, Yagi A, Kaji S, Yamauchi T: Effects of flunarizine therapy on intractable epilepsy. Arzneimittelforschung, 1989, 39, 793-798.

[6]. Overweg J, Binnie CD, Meijer JW, Meinardi H, Nuijten ST, Schmaltz S, Wauquier A: Double-blind placebocontrolled trial of flunarizine as add-on therapy in epilepsy. Epilepsia, 1984, 25, 217-22

[7]. Starreveld E, de Beukelaar F, Wilson AF, McLean DR, Findlay HP: Double-blind cross-over placebo controlled study of flunarizine in patients with therapy resistant epilepsy. Can J Neurol Sci, 1989, 16, 187-190.

[8]. Czuczwar SJ, Turski WA, Kleinrok Z. Interaction of calcium channel blockers and excitatory amino acid antagonists with conventional antiepileptic drugs. CNS Drug Rev 1996;2:452-67.

[9]. Kaminski R, Jasiñski M, Jagieo-Wójtowicz E, Kleinrok Z, Czuczwar SJ. Effect of amlodipine upon the protective activity of antiepileptic drugs against maximal electroshock-induced seizures in mice. Pharmacol Res 1999;40:319-25.

[10]. Stefani A, Spadoni F, Bernardi G. Voltage-activated calcium channels: targets of antiepileptic drug therapy? Epilepsia 1997;38:959-65.

[11]. Takahashi T, Momiyama A. Different types of calcium channels mediate central synaptic transmission. Nature 1993;366:156-8.

[12]. Burges R, Moisey D. Unique pharmacologic properties of amlodipine. Am J Cardiol 1994;73:2A-9A.

[13]. Furukawa T, Nukada T, Suzuki K, Fujita Y, Mori Y, Nishimura M, et al. Voltage and pH dependent block of cloned N-type Ca2+ channels by amlodipine. Br J Pharmacol 1997;121:1136-40.

[14]. McLean MJ. Gabapentin. Epilepsia 1995; 36:S73-S86.

[15]. Watson WP, Robinson E, Little HJ. The novel anticonvulsant, gabapentin, protects against both convulsant and anxiogenic aspects of the ethanol withdrawal syndrome. Neuropharmacology.1997;36:1369-1375

[16]. Rizwan AN, Ali A, Dua Y. Effects of gabapentin and antidepressant drug combinations on convulsions and memory in mice. Pol J Pharmacol 2003;55:965-71.

[17]. Gurney ME, Cutting FB, Zhai P, Doble A. Benefit of vitamin E, riluzoleand gabapentin in a transgenic model of familial amyotrophiclateral sclerosis. Ann Neurol 1996;39:147-57.

[18]. Taylor CP, Gee NS, Su TZ. A summary of mechanistic hypothesis of gabapentin pharmacotherapy. Epilepsy Res 1998;29:233-49.

[19]. Brown JP, Gee NS. Cloning and deletion mutagenesis of the alpha 2 delta calcium channel subunit from porcine cerebral cortex: Expression of a soluble form of the protein that retains gabapentin binding activity. J Biol Chem 1998:273:25458-65.

[20]. Zhang X, Velumian AA, Jones OT, Carlen PL. Modulation of high-voltage-activated calcium channels in dentate granule cells by topiramate. Epilepsia. 2000;41(suppl 1):S52-60.

[21]. White HS, Brown SD, Woodhead JH, Skeen GA, Wolf HH. Topiramate enhances GABA-evoked chloride currents in murine brain neurons and increases seizure threshold. Epilepsy Res. 1997;28:167-79. 
[22]. Luszczki JJ, Czuczwar SJ. Gabapentin synergistically interacts with topiramate in the mouse maximal electroshock seizure model: an isobolographic analysis. Pharmacol Rep 2006;58:944-54.

[23]. Macdonald RL, Greenfield LJ. Mechanism of action of new antiepileptic drugs. Curr Opin Neurol 1997; 10: 121-128. 